\title{
An Automated Quality Assessment and Control Algorithm for Surface Radiation Measurements
}

\author{
C.N. Long* and Y. Shi
}

Pacific Northwest National Laboratory, Richland, WA, USA

\begin{abstract}
We present an automated algorithm for testing surface broadband radiation measurements to detect erroneous data. The methodology has been developed using data from the US Department of Energy Atmospheric Radiation Measurement (ARM) Program. The testing includes physically possible limits as determined by the World Meteorological Organization (WMO) Baseline Surface Radiation Network, as well as user configurable limits based on climatological analysis of data collected at the measurement site. The algorithm can be run in near real time, or more typically on a daily basis. Additionally, longer monthly or yearly runs can be used to assess more subtle tendencies and problems in the data through evaluation of daily summaries of quality flagging.
\end{abstract}

\section{INTRODUCTION}

Our surface radiation quality testing methodology (hereafter called QCRad) in essence uses climatological analyses of the surface radiation measurements themselves to define reasonable limits for testing the data for unusual data values. The main assumption here is that the majority of the climatological data are "good" data, which for field sites operated with nominal care such as those of the US Department of Energy Atmospheric Radiation Measurement (ARM) Program [1], the National Oceanic and Atmospheric Administration SURFRAD network [2], and the World Meteorological Organization (WMO) Baseline Surface Radiation Network [3] is a reasonable assumption. Data which fall outside the normal range of occurrences are labeled either "indeterminate" (meaning that the measurements are physically possible, but rarely occurring, and thus we cannot tell whether the values are "good" or not) or "bad", depending on how far outside the normal range the particular data reside. The methodology not only sets fairly standard maximum and minimum value limits, but includes many cross-comparisons based on experience gained regarding instrument behavior in the field in development of ARM Value Added Products (VAPs) such as the Diffuse IR Loss Correction VAP [4] and the Best Estimate Flux VAP [5].

\section{DEFINITIONS}

We refer to various quantities related to the measurements and tests in the text. While many of these are more fully discussed where appropriate, we provide here a brief listing for reference:

- $\quad \mathrm{SZA}=$ solar zenith angle

- $\quad \mu_{0}=$ Cosine of SZA

- $\quad$ NOTE: In the formulas used for QCRad testing, if $\mathrm{SZA}>90^{\circ}, \mu_{0}$ is set to 0.0 in the formula

- $\mathrm{S}_{0}=$ solar constant at mean Earth-Sun distance, QCRad uses a value of $1368 \mathrm{Wm}^{-2}$

*Address correspondence to this author at the Pacific Northwest National Laboratory, Richland, WA, USA; E-mail: chuck.long@pnl.gov
- $\quad \mathrm{AU}=$ Earth-Sun distance in Astronomical Units [1 $\mathrm{AU}=$ mean $\mathrm{E}-\mathrm{S}$ distance]

- $\quad \mathrm{S}_{\mathrm{a}}=\mathrm{S}_{0} / \mathrm{AU}^{2}=$ solar constant adjusted for Earth-Sun distance

- $\quad \boldsymbol{\sigma}=$ Stephan-Boltzman constant $=5.67 \times 10^{-8} \mathrm{Wm}^{-2} \mathrm{~K}^{-4}$

- $\mathrm{T}_{\mathrm{a}}=$ air temperature in Kelvin [must be in range $170 \mathrm{~K}$ $\left.<\mathrm{T}_{\mathrm{a}}<350 \mathrm{~K}\right]$

- $\mathrm{T}_{\mathrm{d}}=$ pyrgeometer dome temperature

- $\mathrm{T}_{\mathrm{c}}=$ pyrgeometer case temperature

- $\mathrm{T}_{\mathrm{snw}}=$ temperature limit for albedo limit test, temp at which "snow" limit is used

- Shortwave (SW) irradiance: irradiance nominally over the range 0.3-3.0 microns

- Longwave (LW) irradiance: irradiance nominally over the range 5.0-50.0 microns

- Global SW (GSW): downwelling SW measured by unshaded pyranometer

- $\quad$ Diffuse (Dif) SW: SW measured by shaded pyranometer

- $\quad$ Direct Normal (DirN) SW: direct SW measured with a detector perpendicular to the Sun's rays

- Direct (Dir) SW: direct component of SW

$\circ \quad$ [(Direct Normal SW $\left.) \times \mu_{0}\right]$

- $\quad$ Sum SW $=[$ Diffuse $S W+$ Direct SW $]$

- $\quad$ SWdn: total downwelling SW, can be either GSW or Sum SW

- $\quad$ SWup: upwelling SW measured by a pyranometer

- Clear-sky (Clr) SW: estimated clear (i.e. cloudless) sky downwelling SW

- $\quad$ LWdn: downwelling LW measured by a pyrgeometer

- $\quad$ LWup: upwelling LW measured by a pyrgeometer 
- $\quad$ Prs: surface station pressure in millibars (NOT adjusted to sea level)

\section{DATA TESTS APPLIED}

For the QCRad methodology, three levels of testing are in many cases applied. These are defined according to their severity as far as data falling outside the limits. A data Quality Control (QC) flag value of " 0 " indicates that the data have not failed any of the tests applied, and as far as we have tested represent "good" data. The greater the QC flag value, the more the data fall outside the normal range of values typically seen for that quantity. The QCRad code applies testing using the largest limits first, and then if the data passes, applies the next smaller limits testing. Thus the flag value represents at what level of severity the tested data failed. The larger the QC flag integer value, the more severe the testing failure. In general, an odd QC flag value indicates a measurement that falls below the corresponding minimum limit, while an even value indicates a measurement that falls above the corresponding maximum test limit. The one exception is for a specific test not being possible, usually because some value needed to perform the test is not available. In this case, a QC flag value of "-1" is assigned, and simply means that the data could not be tested in that way. For example, if the ambient air temperature measurements are missing or deemed "bad", then the tests based on using the air temperature cannot be performed, and the corresponding flags are set to "-1". A flag of " -1 " does NOT mean the data are "bad", merely that the particular test could not be applied, thus it is unknown if that datum would have passed or failed had it been tested that way. A complete listing of all QC flag values and their meanings is given in Appendix 1.

For the QCRad VAP, we set the smallest testing limits to reflect the range within which the majority of reasonable data typically fall. We then set the next largest limits to include data that have been recorded at the site and have been shown to be possible, yet that occur rarely and so might also be anomalous data. In this latter case, the QC flags are set to a value of either 1 or 2 as appropriate, but the data value itself is left in the output files. The intent is to flag these values as "possible, but rarely occurring", and it is left to the user to determine whether they wish to use these data or not. Any data that fall outside of the second level of testing are deemed to be in error, the QC flag value is set to either 3 or 4 , and the corresponding data value is set to a "bad" value of "-9999.0", i.e. the data value is not given to the user.

It should be noted that global SW data, the temporal resolution has an impact on what data can be considered reasonable. Brief excursions exceeding the corresponding clear-sky SW amount of a few minutes duration do occur under partly cloudy skies because of the enhancement of the diffuse SW and then the direct SW not being blocked by cloud for brief periods. The equatorial tropical western Pacific ARM sites have often recorded values exceeding $1400 \mathrm{Wm}^{-2}$ for a few minutes duration confirmed with both the unshaded pyranometer and the sum of the direct and diffuse measurements. However, longer temporal averaging then tends to mask these brief larger excursions. Thus more liberal limits used for 1-minute resolution data such that these larger real excur- sions are not mislabeled as "bad" data would be too liberal for longer average data wherein the effects on the average values of these brief excursions are masked. Thus in effect the longer the data averaging time, the more restrictive the proper testing limits should be.

For the shortwave (SW) variables, limits are typically set using the cosine of the solar zenith angle as the independent variable, plus a constant offset to account for measurement uncertainties. For the longwave (LW), some tests apply simple maximum and minimum limits on acceptable values. Other tests use the high degree of correlation known to exist between the surface 2-meter ambient air temperature $\left(T_{a}\right)$ and typical ranges of measured LW for the particular climate and site.

\section{TEMPERATURES}

The QCRad code uses air temperature measurements, if available, to help determine limits and tests for reasonable data. The availability of air temperature measurements is especially beneficial for testing LW data. However, before using any air temperature measurements we need to test them for reasonable values themselves to avoid using erroneous data to test other related data. Thus, if the input data includes pyrgeometer case and dome temperatures, and/or air temperature, then these temperatures are tested by:

$\mathrm{T}_{\min }<\mathrm{T}_{\mathrm{x}}<\mathrm{T}_{\max }$

Where $T_{\min }$ and $T_{\max }$ are user defined minimum and maximum limits, respectively, determined using analysis of climatological data, and $T_{x}$ is the temperature value being tested. Then if each $T_{c}-T_{d}$ pair is within $+/-10 \mathrm{~K}$ of each other, they are included in producing an average of all $\mathrm{T}_{\mathrm{c}}$ and $T_{d}$ values that pass the testing. $T_{a}$ must then fall within $+/-20$ $\mathrm{K}$ of this average, and each individual $\mathrm{T}_{\mathrm{c}}$ and $\mathrm{T}_{\mathrm{d}}$ must fall within $+/-15 \mathrm{~K}$ of this average, else the value is not used and is set to "-9999.0".

\section{PHYSICALLY POSSIBLE LIMITS PER BSRN}

The BSRN is comprised of groups of researchers from around the world dedicated to the long-term, accurate measurement of the surface radiation budget for climate and climate change research purposes, under the auspices of the World Meteorological Organization (WMO) World Climate Research Program (WCRP). The BSRN is also charged with setting the standards by which accurate surface radiation measurements might be accomplished [3,6], including testing for physically reasonable values given the wide range of conditions found over the entire globe. As such, BSRN has established globally physically possible limits for surface radiation measurements [7], which we include in the QCRad testing. For these "globally physically possible" tests, any measurement that falls outside the limit is given a QC flag value of 5 (if it falls below the minimum limit) or 6 (if it falls above the maximum limit), and the corresponding data value is set to "-9999.0". The formulas used for each tested variable are as follows:

\section{Global SWdn}

Min: $-4 \mathrm{Wm}^{-2}$ 


$$
\text { Max: } \mathrm{S}_{\mathrm{a}} \times 1.5 \times \boldsymbol{\mu}_{0}^{1.2}+100 \mathrm{Wm}^{-2}
$$

\section{Diffuse SW}

Min: $-4 \mathrm{Wm}^{-2}$

$$
\text { Max: } \mathrm{S}_{\mathrm{a}} \times 0.95 \times \boldsymbol{\mu}_{0}^{1.2}+50 \mathrm{Wm}^{-2}
$$

\section{Direct Normal SW}

Min: $-4 \mathrm{Wm}^{-2}$

Max: $\mathrm{S}_{\mathrm{a}}$

[for Direct SW, Max: $\mathrm{S}_{\mathrm{a}} \mathrm{x} \boldsymbol{\mu}_{0}$ ]

SWup

Min: $-4 \mathrm{Wm}^{-2}$

Max: $\mathrm{S}_{\mathrm{a}} \times 1.2 \times \boldsymbol{\mu}_{0}^{1.2}+50 \mathrm{Wm}^{-2}$

$\underline{\mathrm{LWdn}}$

Min: $40 \mathrm{Wm}^{-2}$

Max: $700 \mathrm{Wm}^{-2}$

LWup

Min: $40 \mathrm{Wm}^{-2}$

Max: $900 \mathrm{Wm}^{-2}$

\section{EXTREMELY RARE MINIMUM LIMITS PER BSRN}

Additionally, the QCRad code uses the BSRN defined second level testing limits for minimum acceptable values for SW measurements as follows. While some pyranometers do produce more negative night time offsets due to IR loss than even the $-4 \mathrm{Wm}^{-2}$ limits in the previous section while still operating properly, these larger offsets should be corrected in the data through published methods [4]. Thus values lower than $-4 \mathrm{Wm}^{-2}$ indicate to the user that the data in question have not been properly corrected for IR loss, and are to be considered questionable at least.

Global SWdn

Min: $-2 \mathrm{Wm}^{-2}$

Diffuse SW

Min: $-2 \mathrm{Wm}^{-2}$

Direct Normal SW

Min: $-2 \mathrm{Wm}^{-2}$

SWup

Min: $-2 \mathrm{Wm}^{-2}$

\section{COMPARISON TESTS PER BSRN}

Finally, BSRN has defined the following comparison tests which are included. Note that the first two tests are "non-definitive", i.e. while data may fail these tests it is unknown which of the data used to calculate the ratio are problematic. In these cases, the corresponding QC flags are set to values of 1 or 2 , and no corresponding data values themselves are set to "-9999.0". For the SWup test, failure results in QC flag values of 5 or 6, and the SWup data set to "9999.0".

Ratio of Global SW over Sum SW:

$(\mathrm{SWdn}) /(\mathrm{Sum} \mathrm{SW})$ should be within $+/-8 \%$ of 1.0 for $\mathrm{SZA}<75^{\circ}$, Sum $>50 \mathrm{Wm}^{-2}$

$(\mathrm{SWdn}) /(\mathrm{Sum} \mathrm{SW})$ should be within $+/-15 \%$ of 1.0 for $93^{\circ}>\mathrm{SZA}>75^{\circ}, \mathrm{Sum}>50 \mathrm{Wm}^{-2}$

For Sum SW $<50 \mathrm{Wm}^{-2}$, test not possible

Diffuse Ratio (where "Dif" = diffuse):

$($ Dif SW $) /(\mathrm{SWdn})<1.05$ for $\mathrm{SZA}<75^{\circ}, \mathrm{SWdn}>50 \mathrm{Wm}^{-2}$

$($ Dif $\mathrm{SW}) /(\mathrm{SWdn})<1.10$ for $93^{\circ}>\mathrm{SZA}>75^{\circ}, \mathrm{SWdn}>$ $50 \mathrm{Wm}^{-2}$

For Global $\mathrm{SW}<50 \mathrm{Wm}^{-2}$, test not possible

SWup comparison

SWup $<$ (Sum SW) [or SWdn if Sum SW missing]

For Sum SW [or SWdn] $>50 \mathrm{Wm}^{-2}$

For Sum SW [or SWdn] $<50 \mathrm{Wm}^{-2}$, test not possible

If SWup $>$ (Sum SW) AND SWup $>($ SWdn $)$,

Swup = "bad"

\section{CLIMATOLOGICAL (CONFIGURABLE) LIMITS}

All of the previous limits discussed so far are fixed into the QCRad code. What follows are limits that are configured for each site based on analyses of several years of the site data. Those limits labeled " $1{ }^{\text {st }}$ level" are the "smallest" testing limits described previously, while those labeled " 2 nd level" are the second set of limits where failure causes the data value being tested to be set to "-9999.0". The specific formulas for these tests are as follows, where $\mathrm{D}_{\mathrm{X}}$ refers to the $2^{\text {nd }}$ level settings, and $C_{X}$ refers to the $1^{\text {st }}$ level settings:

\section{Global SWdn}

$$
\begin{aligned}
& \text { Max: } S_{a} \times D_{1} \times \boldsymbol{\mu}_{0}^{1.2}+55 \mathrm{Wm}^{-2}\left(2^{\text {nd }} \text { level }\right) \\
& \text { Max: } S_{a} \times C_{1} \times \boldsymbol{\mu}_{0}^{1.2}+50 \mathrm{Wm}^{-2}\left(1^{\text {st }} \text { level }\right)
\end{aligned}
$$

Diffuse SW

$$
\begin{aligned}
& \text { Max: } S_{a} \times D_{2} \times \mu_{0}^{1.2}+35 \mathrm{Wm}^{-2}\left(2^{\text {nd }} \text { level }\right) \\
& \text { Max: } S_{a} \times C_{2} \times \boldsymbol{\mu}_{0}^{1.2}+30 \mathrm{Wm}^{-2}\left(1^{\text {st }} \text { level }\right)
\end{aligned}
$$

Direct Normal SW

$$
\begin{aligned}
& \text { Max: } \mathrm{S}_{\mathrm{a}} \times \mathrm{D}_{3} \times \boldsymbol{\mu}_{0}^{0.2}+15 \mathrm{Wm}^{-2}\left(2^{\text {nd }} \text { level }\right) \\
& \text { [for Dir, Max: } \left.\mathrm{S}_{\mathrm{a}} \times \mathrm{D}_{3} \times \boldsymbol{\mu}_{0}{ }^{1.2}+15 \mathrm{Wm}^{-2} \text { ] (2 }{ }^{\text {nd }} \text { level }\right) \\
& \text { Max: } \mathrm{S}_{\mathrm{a}} \times \mathrm{C}_{3} \times \boldsymbol{\mu}_{0}^{0.2}+10 \mathrm{Wm}^{-2}\left(1^{\text {st }} \text { level }\right) \\
& \text { [for Dir, Max: } \left.\mathrm{S}_{\mathrm{a}} \times \mathrm{C}_{3} \times \boldsymbol{\mu}_{0}{ }^{1.2}+10 \mathrm{Wm}^{-2} \text { ] (1 }{ }^{\text {st }} \text { level }\right)
\end{aligned}
$$

SWup

$$
\text { Max: } \mathrm{S}_{\mathrm{a}} \times \mathrm{D}_{4} \times \boldsymbol{\mu}_{0}^{1.2}+55 \mathrm{Wm}^{-2}\left(2^{\text {nd }} \text { level }\right)
$$




$$
\text { Max: } \mathrm{S}_{\mathrm{a}} \times \mathrm{C}_{4} \times \boldsymbol{\mu}_{0}^{1.2}+50 \mathrm{Wm}^{-2}\left(1^{\text {st }} \text { level }\right)
$$

$\underline{L W d n}$

Min: $\mathrm{D}_{5} \mathrm{Wm}^{-2}\left(2^{\text {nd }}\right.$ level $)$

Max: $\mathrm{D}_{6} \mathrm{Wm}^{-2}\left(2^{\text {nd }}\right.$ level)

Min: $\mathrm{C}_{5} \mathrm{Wm}^{-2}\left(1^{\text {st }}\right.$ level $)$

Max: $\mathrm{C}_{6} \mathrm{Wm}^{-2}\left(1^{\text {st }}\right.$ level $)$

LWup

$$
\begin{aligned}
& \text { Min: } \mathrm{D}_{7} \mathrm{Wm}^{-2}\left(2^{\text {nd }} \text { level }\right) \\
& \text { Max: } \mathrm{D}_{8} \mathrm{Wm}^{-2}\left(2^{\text {nd }} \text { level }\right) \\
& \text { Min: } \mathrm{C}_{7} \mathrm{Wm}^{-2}\left(1^{\text {st }} \text { level }\right) \\
& \text { Max: } \mathrm{C}_{8} \mathrm{Wm}^{-2}\left(1^{\text {st }} \text { level }\right)
\end{aligned}
$$

CLIMATOLOGICAL (CONFIGURABLE) COMPARISONS

The QCRad code makes use of cross-comparisons between measured and calculated variables. One calculated variable is a generic estimate of the expected clear-sky downwelling SW as a product from a power law formula where the user specifies the "a" and "b" coefficients (see below), and again the cosine of the solar zenith angle $\left(\boldsymbol{\mu}_{0}\right)$ is used as the independent variable. The use of a power law formulation has been shown to well represent downwelling SW for clear skies [8,9]. The "a" and "b" coefficients are determined by fitting to user identified clear-sky data covering a range of solar zenith angles as experienced at the particular site. The clear-sky SW estimate is used in the first test listed below, which tests for whether the solar tracker was properly tracking the sun. If the ratio of the measured over clear-sky SWdn is greater than 0.85 , this indicates that most of the possible SWdn is reaching the unshaded pyranometer, i.e. there is no significant cloudiness between the sun and the instrument. At the same time, if the corresponding ratio of the shaded pyranometer (supposedly measuring the diffuse $\mathrm{SW}$ ) over the unshaded pyranometer is also greater than 0.85 , then the "shaded pyranometer" has become unshaded since these are mutually exclusive conditions. For times when there is a cloud between the sun and the unshaded pyranometer this test does not work, but then the "sum of direct plus diffuse" is valid since there would not be any significant direct component anyway. The specific formula for the "Tracker off" test is as follows:

$$
\text { Using } \mathrm{ClrSW}=\left[\mathbf{a} / \mathrm{AU}^{2}\right] \times \mu_{0}^{\mathbf{b}},
$$

where " $a$ " and " $b$ " are configured by user

Then for diffuse $\mathrm{SW}>50 \mathrm{Wm}^{-2}$,

IF $($ Sum SW) $/ \mathrm{ClrSW}>0.85$ [or Global SW if Sum SW missing]

$\underline{\text { AND }}$ if Dif/(Sum SW) $>0.85$ [or Global SW if Sum SW missing]

THEN the tracker is not properly following the sun

Another calculated variable is an estimate of the expected clear-sky diffuse SW produced by Rayleigh (molecular) scattering only. No non-overcast diffuse measurement, which occurs with at least some additional scattering due to the presence of aerosols or haze in the atmospheric column, should fall below the Rayleigh limit. If the measured station pressure (not adjusted to equivalent sea level pressure) is available, then it is used in the formula given below, else a generic station pressure set by the user is used in the calculation. This formula was produced as part of the development of the ARM Diffuse IR Loss Correction VAP, and details are presented in [4]. The Rayleigh diffuse $\mathrm{SW}\left(\mathrm{R}_{\mathrm{L}}\right)$ is estimated using:

$\mathrm{R}_{\mathrm{L}}=\mathrm{a} \boldsymbol{\mu}_{0}+\mathrm{b} \boldsymbol{\mu}_{0}{ }^{2}+\mathrm{c} \boldsymbol{\mu}_{0}{ }^{3}+\mathrm{d} \boldsymbol{\mu}_{0}{ }^{4}+\mathrm{e} \boldsymbol{\mu}_{0}{ }^{5}+\mathrm{f} \boldsymbol{\mu}_{0}$ Prs

where:

$\mathrm{a}=209.3$

$\mathrm{b}=-708.3$

$\mathrm{c}=1128.7$

$\mathrm{d}=-911.2$

$\mathrm{e}=287.85$

$\mathrm{f}=0.046725$

$\boldsymbol{\mu}_{0}=$ cosine of the solar zenith angle

$\operatorname{Prs}=$ station surface pressure in millibars

If the global SW is greater than $50 \mathrm{Wm}^{-2}$, and (Diffuse $\mathrm{SW}) /($ Global SW) is less than 0.8 , and diffuse $\mathrm{SW}$ is less than $\left(\mathrm{R}_{\mathrm{L}}-1.0\right)$, then diffuse is determined to be in error and the QC flag is set to " 8 ".

For testing the upwelling SW, we use the air temperature if available to refine the limits for whether snow covered ground (with attendant high surface albedo) is possible. When the ground is completely covered with snow, then virtually all the net radiative energy input into the surface goes toward changing the snow from solid to liquid or vapor, i.e. changing the phase. Thus snow covered ground cannot be more than zero degrees Centigrade in temperature (though it can be lower in temperature). Thus, in turn, the snow covered ground cannot drive the air above it (through conduction and convection) to air temperatures greater than freezing until significant portions of the ground become uncovered through snow melt. Even blowing air over snow covered ground (over the surrounding domain) will normally remain near freezing due to low level turbulent mixing. Thus we set a limit in air temperature above which the allowable albedo limits are much more restrictive. This air temperature setting must take into account the possibility that during snow melt, as the ground becomes more and more uncovered, the air temperature CAN then climb significantly above freezing, and how much above depends to large extent on the nature of the surface roughness and/or vegetation type present. For example at the ARM Southern Great Plains (SGP) Central Facility there is usually tall dried stalks standing in the area where the radiometer systems are located, while at the same time deep snow fall events (for example a foot of snow) are unusual. Thus for the SGP, we use an air temperature limit of $8^{\circ} \mathrm{C}$. For data that occur when temperatures are above $8^{\circ} \mathrm{C}$, the allowable albedo is much more restricted than when 
the air temperature falls below $8^{\circ} \mathrm{C}$. Using the air temperature as an aid in determining how restrictive an albedo limit to use does not guarantee that the colder data are well tested, since lower air temperatures can and often do occur in winter months with no snow present. But using an air temperature aid certainly does improve the testing of data during warmer conditions than just using an albedo limit all year that would allow for snow covered ground. The specific test for the upwelling SW is as follows:

SWup $<\mathrm{N}_{\mathrm{X}} \mathrm{x}$ (Sum SW) $+25 \mathrm{Wm}^{-2}$ [or Global SW if

Sum SW missing] where $\mathrm{N}_{X}$ is the appropriate 1 st or 2nd level setting as described below

$$
\begin{aligned}
& \text { For Sum } \mathrm{SW} \text { [or Global } \mathrm{SW} \text { ] }>50 \mathrm{Wm}^{-2} \\
& \mathrm{D}_{9} \text { and } \mathrm{C}_{9} \text { if } \mathrm{T}_{\mathrm{a}}>\mathrm{T}_{\text {snw }} \text { limit ("normal" } \\
& \text { ground cover) } \\
& \mathrm{D}_{10} \text { and } \mathrm{C}_{10} \text { if } \mathrm{T}_{\mathrm{a}}<\mathrm{T}_{\text {snw }} \text { limit (ground may } \\
& \quad \text { be "snow covered") } \\
& \mathrm{T}_{\text {snw }}=\text { Temperature limit for test, degrees } \mathrm{C}, \\
& \quad>0^{\circ} \mathrm{C}
\end{aligned}
$$
ble

For Sum SW [or Global SW] $<50 \mathrm{Wm}^{-2}$, test not possi-

If SWup is greater than the 1st level limit, but less than the 2nd level limit, then the QC flag is set to "1" for Ta > Tsnw or "2" for Ta $<$ Tsnw. Else if SWup is greater than the 2nd level limit, SWup is set to "bad", and the QC flag is set to "3" or "4" as appropriate.

The air temperature measurements are also used to test the pyrgeometer case and dome temperatures directly. Given that the case and dome temperatures are used to the $4^{\text {th }}$ power in the formulations that calculate the LW irradiance, even a few degrees error can produce significant error in the LW calculations. Since all ARM downwelling radiometers are ventilated, and the upwelling radiometers are protected by sun shields, the case and dome temperatures should always be within some small range of the ambient air temperatures. Thus we test the case and dome temperatures by setting a +/- temperature offset from the air temperature as follows:

$\mathrm{T}_{\mathrm{a}}-\mathrm{C}_{17}<\left(\mathrm{T}_{\mathrm{c}}\right.$ or $\left.\mathrm{T}_{\mathrm{d}}\right)<\mathrm{T}_{\mathrm{a}}+\mathrm{C}_{17}\left(1^{\text {st }}\right.$ level $)$

(for both $\mathrm{LW}_{\mathrm{dn}}$ and $\mathrm{LW}_{\text {up }}$ instruments. If have all 3, can determine "bad" one)

If $T_{a}$ not available, test not possible.

If a case or dome temperature falls outside this range, then the QC flag is set to a value of 3 if too low, and 4 if too high.

Given the ventilation of the pyrgeometers, each individual instrument's dome temperature should normally be nearly the same as the case temperature, with the dome temperature usually being lower than the case temperature due to radiational cooling to the colder sky. Thus we test to make sure the case and dome temperature difference is within reasonable limits as follows:

$\mathrm{C}_{18}<=\left(\mathrm{T}_{\mathrm{c}}-\mathrm{T}_{\mathrm{d}}\right)<\mathrm{C}_{19}$

If $\mathrm{T}_{\mathrm{c}}$ and/or $\mathrm{T}_{\mathrm{d}}$ "bad", test not possible.
If the case-dome temperature difference falls outside this range, then the QC flag is set to a value of 3 if too low, and 4 if too high.

For upwelling and downwelling LW irradiance, there is a high degree of correlation between the ambient air temperature and the irradiance values. As noted by Ohmura [10], under clear (i.e. cloudless) skies typically about $2 / 3$ of the measured downwelling LW at the surface comes from the first $100 \mathrm{~m}$ of atmosphere above the instrument, with about $90 \%$ of the signal coming from the lowest $1 \mathrm{~km}$ of the atmosphere. This occurs because the warmest and highest concentration of greenhouse gases resides near the surface, and turbulent mixing in the boundary layer produces a strong correlation between the temperature profile and the nearsurface air temperature. Thus we use the air temperature to set comparative limits to test for reasonable values of the downwelling and upwelling LW as follows:

\section{LWdn to Air Temperature comparison}

$$
\begin{aligned}
& \mathrm{D}_{11} \times \boldsymbol{\sigma}_{\mathrm{T}_{\mathrm{a}}^{4}}^{4}<\mathrm{LWdn}<\boldsymbol{\sigma} \mathrm{T}_{\mathrm{a}}^{4}+\mathrm{D}_{12}\left(2^{\text {nd }} \text { level }\right) \\
& \mathrm{C}_{11} \times \boldsymbol{\sigma}_{\mathrm{a}}^{4}<\mathrm{LWdn}<\boldsymbol{\sigma}_{\mathrm{a}}^{4}+\mathrm{C}_{12}\left(1^{\text {st }} \text { level }\right)
\end{aligned}
$$

\section{LWup to Air Temperature comparison}

$$
\begin{aligned}
& \boldsymbol{\sigma}\left(\mathrm{T}_{\mathrm{a}}-\mathrm{D}_{13} \mathrm{~K}\right)^{4}<\mathrm{LWup}<\boldsymbol{\sigma}\left(\mathrm{T}_{\mathrm{a}}+\mathrm{D}_{14} \mathrm{~K}\right)^{4}\left(2^{\text {nd }} \text { level }\right) \\
& \boldsymbol{\sigma}\left(\mathrm{T}_{\mathrm{a}}-\mathrm{C}_{13} \mathrm{~K}\right)^{4}<\mathrm{LWup}<\boldsymbol{\sigma}\left(\mathrm{T}_{\mathrm{a}}+\mathrm{C}_{14} \mathrm{~K}\right)^{4}\left(1^{\text {st }} \text { level }\right)
\end{aligned}
$$

Similarly, the downwelling LW is compared to the corresponding upwelling LW to test for consistency. Similar to the air temperature, the upwelling and downwelling LW over land surfaces is physically correlated, and thus should fall within certain values in relation to one another. The specific limits for comparison of the upwelling and downwelling LW are as follows:

\section{LWdn to Lwup comparison}

$$
\begin{aligned}
& \text { LWup- } \mathrm{D}_{15} \mathrm{Wm}^{-2}<\text { LWdn }<\text { LWup }+\mathrm{D}_{16} \mathrm{Wm}^{-2}\left(2^{\text {nd }}\right. \\
& \text { level }) \\
& \text { LWup-C } \\
& \text { level })
\end{aligned}
$$

For the above LW tests, if the value of the variable being tested (LWdn or LWup) falls outside the limits, the QC flag is set to "1" if less than the 1st level limit, but greater than the 2nd level limit; "2" if greater than the 1st level limit, but less than the 2nd level limit; " 3 " if less than the 2nd level limit, or "4" if greater than the 2nd level limit. For QC flags greater than a value of "2", the data value is set to "bad" (i.e. -9999.0).

\section{GLOBAL SW CORRECTIONS}

Studies have shown $[11,12]$ that unshaded pyranometer measurements suffer IR loss similar to shaded pyranometer diffuse SW measurements. An ARM VAP has been developed [4] to correct the diffuse IR loss, and another based on the same methodology to deal with the IR loss in the unshaded pyranometer measurements [13]. In the QCRad VAP, generic correction coefficients, obtained through historical 
data analyses at each site, can be applied to the unshaded and shaded pyranometer measurements if desired. In the case of the ARM data used here, a correction for IR loss in the diffuse SW measurements has already been applied.

ARM radiometers are typically replaced each year with newly calibrated units, though at different dates. To nominally correct for IR loss in the global SW data, we examined all the data from these different radiometer pairs, separated as moist and dry modes as determined by the relative humidity and the differences between the pyrgeometer case temperature and the effective sky brightness temperature per [4]. The night time global SW data is then compared to the detector flux, and generic correction coefficients are obtained (see Table 1, Appendix 2). The generic correction coefficients are then used to nominally correct for IR loss in the unshaded pyranometer measurements for data testing (see discussion corresponding to Figs. $(4,5))$.

\section{EXAMPLE PLOTS OF TESTING AND LIMITS}

\section{SW Examples}

Three years of radiation measurement data (1997, 1999, and 2002) from the twenty Extended Facilities of the ARM Southern Great Plains (SGP) network were examined to determine the appropriate climatological limits for all SGP network facilities (see Table 1, Appendix 2). The following plots illustrate the various tests outlined in the preceding sections, using examples from the SGP Central Facility. The data from the ARM Diffuse Correction VAP [4] were used as input. Fig. (1) shows the maximum limits used for downwelling total (global) SW testing, as well as 15-minute averages of the unshaded pyranometer data from 1997. Most data fall below the $1^{\text {st }}$ level limit (green) as expected, with only some few (4 points) data falling above the $2^{\text {nd }}$ level (blue) limit. The "thickness" of these limit lines on the plot are caused by the changes in Earth-Sun distance through the year. The yellow line is the estimated clear-sky SW used in the solar tracker alignment testing described previously.

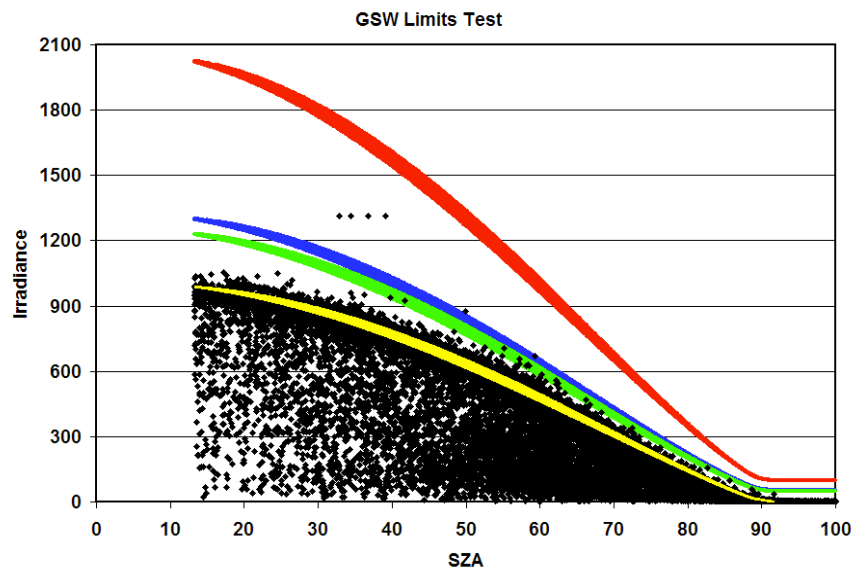

Fig. (1). 15-minute averages of downwelling total (global) SW (black), the $1^{\text {st }}$ (green), $2^{\text {nd }}$ (blue) and BSRN Physically Possible (red) maximum limits used in testing. Yellow represents the estimated clear-sky downwelling SW.

Fig. (2) is similar to Fig. (1), but for diffuse SW. In this plot, the pink dots represent the data that have failed the solar tracker alignment testing. Note that no data have failed the Rayleigh limit testing because that these data have been corrected for IR loss. Fig. (3) shows the results for direct $\mathrm{SW}$. In the case of the direct SW, the maximum limits are comparatively easier to set, since generally a problem such as debris on the window or loss of solar tracking results in a decrease in the direct SW value, and the narrow field-ofview precludes the instrument being subject to positive cloud effect (irradiance greater than the corresponding clear-sky amount) which affect the total and diffuse SW. Here again are some few points above the 2 nd level limit, with 3 points even exceeding the red physically possible limit.

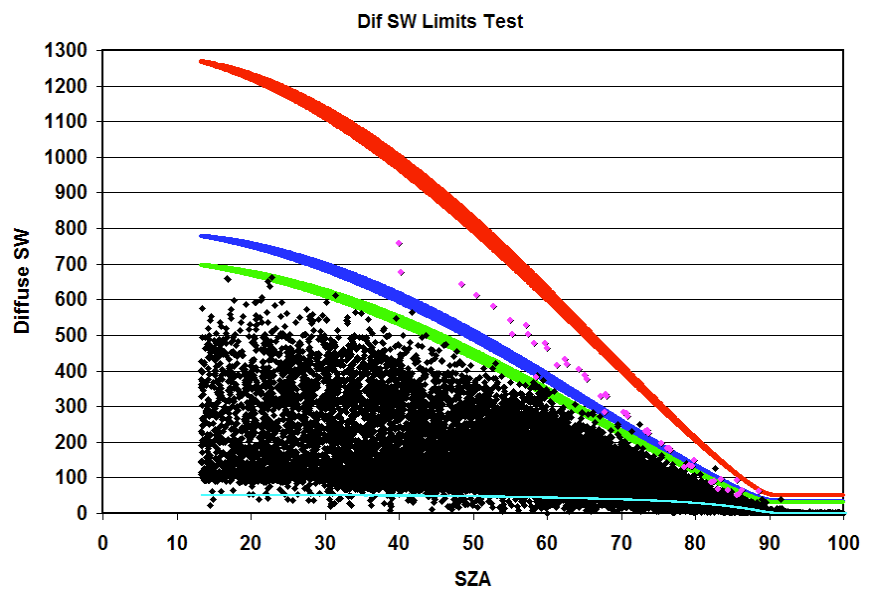

Fig. (2). 15-minute averages of downwelling diffuse SW (black), the $1^{\text {st }}$ (green), $2^{\text {nd }}$ (blue) and BSRN Physically Possible (red) maximum limits used in testing. Light blue is the estimated Rayleigh diffuse limit, pink are the data that failed the solar tracker alignment testing.

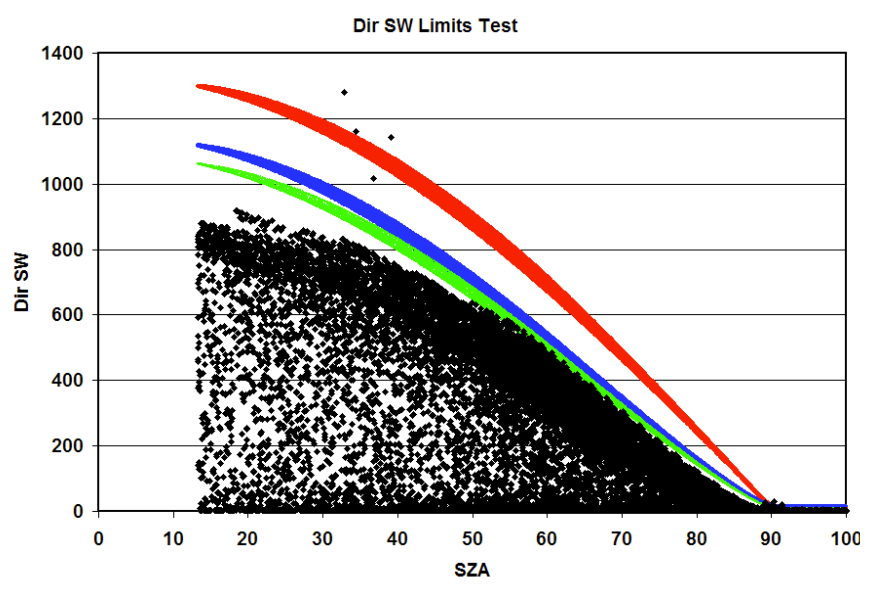

Fig. (3). 15-minute averages of downwelling direct SW (black), the $1^{\text {st }}$ (green), $2^{\text {nd }}$ (blue) and BSRN Physically Possible (red) maximum limits used in testing.

Figs. $(\mathbf{4 , 5})$ show cross-comparison tests with data in the form of ratios. The ratio of the global SW (GSW) measured by the unshaded pyranometer over the sum of the direct plus diffuse SW is shown in Fig. (4). Ideally this ratio should be 1.0 , but instrument characteristics such as cosine response error often produce values away from unity. Additionally, IR loss from the unshaded pyranometer values (numerator) when there is no significant IR loss in the sum (denominator), as in this case where the diffuse SW has been corrected 
for IR loss, produces decreasing ratio values with increasing SZA that resembles cosine response error. Recent research $[11,12,14]$ has indicated that unshaded pyranometers suffer about the same magnitude of IR loss as the same units operated in shaded mode. We determined an average generic set of moist and dry mode night time offset coefficients from examination of many years of data, and apply the same type of detector-only correction methodology as the Diffuse Correction VAP but in this case applied to the unshaded pyranometer data (see [4] for details). In Fig. (4), the red points use uncorrected GSW in the ratio, while the black data use GSW that has been corrected for IR loss using the same methodology as was used to correct the diffuse SW. Note that a significant number of the uncorrected data fail this ratio test because of the lower values at higher SZA, whereas the IR loss corrected GSW ratios pass the testing. Fig. (5) shows the ratio of Diffuse SW over GSW, again with red points using uncorrected GSW, and black using corrected GSW. With IR loss in this case in the denominator, many of the uncorrected points fall above the maximum limit and fail the test, where with corrected GSW these points pass.

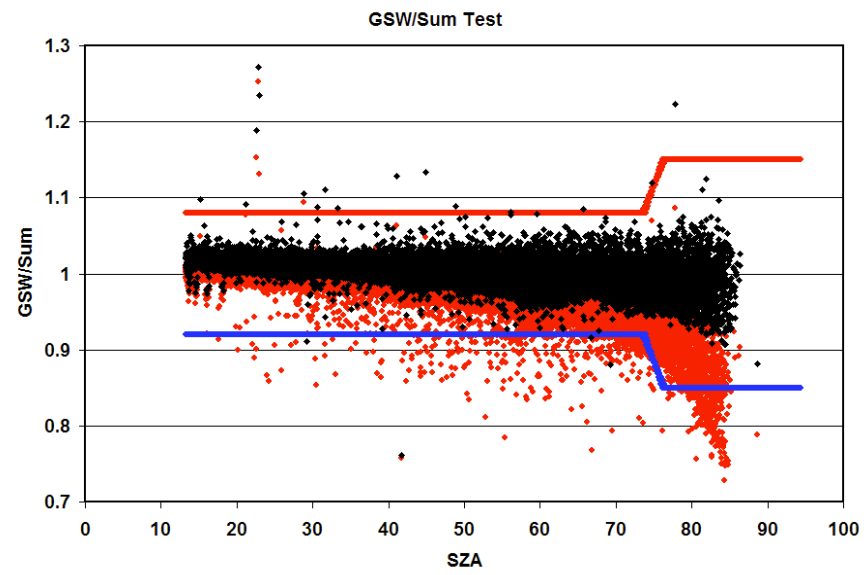

Fig. (4). Ratio of global SW over the sum of direct plus diffuse SW. Red is using original Global SW uncorrected for IR loss, black is corrected data. Red and blue lines denote testing maximum and minimum limits, respectively.

It must be noted that the testing represented in Figs. $(\mathbf{4 , 5})$ are non-definitive, i.e. a test failure gives no indication which of the measurements involved caused the failure. Thus, for these non-definitive test failures none of the corresponding measurements are ever set to "-9999.0", rather only the corresponding QC flag is set to the appropriate value.

For the upwelling SW, we first apply testing similar to that for the GSW, as shown in Fig. (6). In this case, however, we must allow limits that include the possibility of snow covered ground, here with occurrences indicated by the greater SWup values at SZA greater than $55^{\circ}$. Note also the erroneous data with a constant value of about $1350 \mathrm{Wm}^{-2}$ that have been detected by this test. As previously described, we also use the ambient air temperature to screen for when snow covered ground is highly unlikely, and thus can better test the data for air temperatures above the set discrimination limit. Fig. (7) shows the results for our example data using an air temperature limit of $8^{\circ} \mathrm{C}$ for the SGP site. As can be

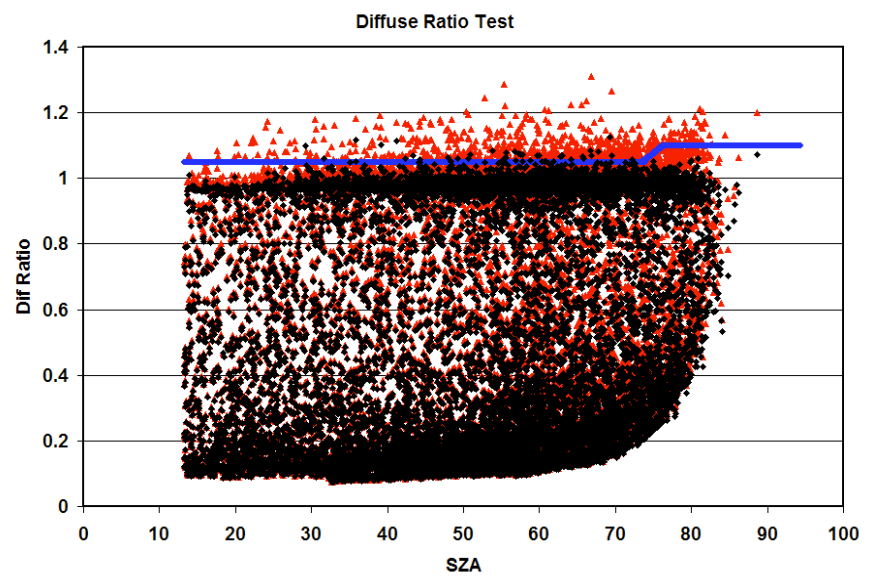

Fig. (5). Ratio of diffuse SW over global SW. Red is original Global SW uncorrected for IR loss, black is corrected data. Blue line denotes testing maximum limit.

seen, there are occurrences of data when the air temperature was at or below $8^{\circ} \mathrm{C}$ that were not snow covered and would have passed the more restrictive higher temperature limit testing, but the snow covered ground data would have failed the more stringent test limits. Using the air temperature to discriminate which limits should be used allowed the snow covered data to pass, but does a much better job of testing the SWup data for warmer times than using the snow covered ground limits at all times.

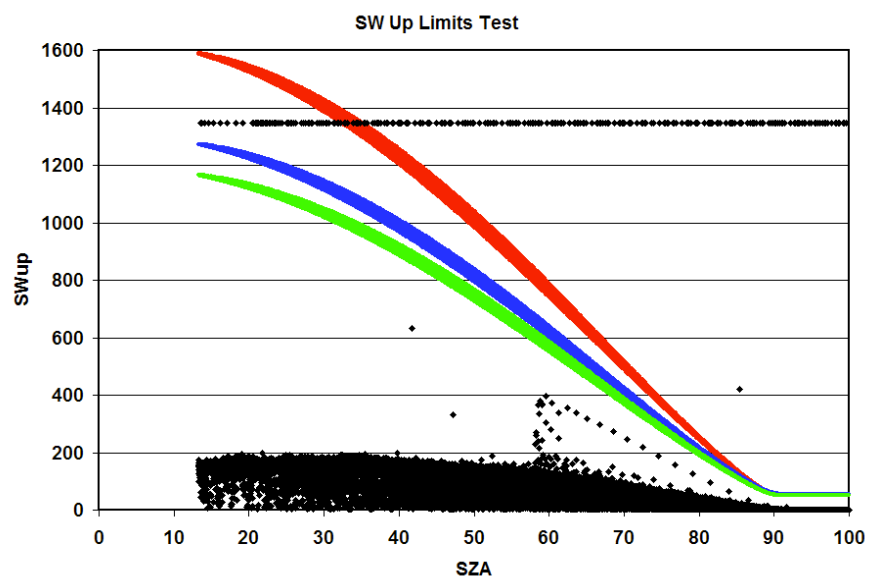

Fig. (6). Same as Fig. (2), but for upwelling SW.

\section{LW Examples}

For the downwelling and upwelling LW, we first use simple maximum and minimum limits as shown in Fig. (8). Fig. (9) illustrates using ambient air temperature for testing the LW data, based on the previously noted high degree of correlation between the two as seen here. The $1^{\text {st }}$ and $2^{\text {nd }}$ level maximum and minimum limits are calculated using the formulas previously given, and provide a nominal shape to the limit curves that approximate the nature of the air temperature-LW relationships. Because of the demonstrated correlation of LW to air temperature, the downwelling and upwelling LW measurements themselves are also correlated, as shown in Fig. (10). Thus we also test and compare these measured values as well, both as an additional constraint, 
and especially for those times when air temperature measurements might not be available.

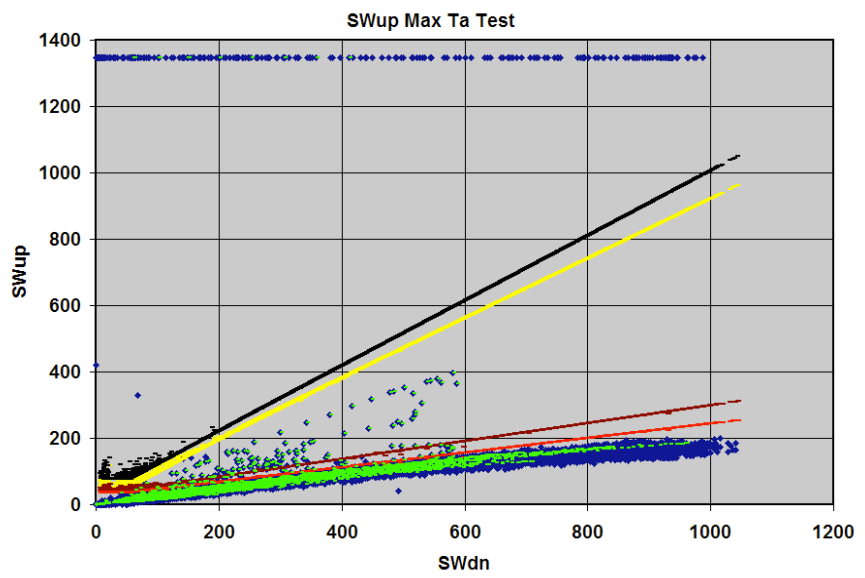

Fig. (7). Upwelling SW testing using air temperature as a limit discriminator. Yellow and black lines represent the $1^{\text {st }}$ and $2^{\text {nd }}$ level limits for when the air temperature is below the set limit, and snow covered ground is possible. Pink and brown lines are the $1^{\text {st }}$ and $2^{\text {nd }}$ level limits for warmer temperatures when snow covered ground is far less likely. Blue is the measured SWup, green is the SWup when the air temperature is below the discrimination limit.
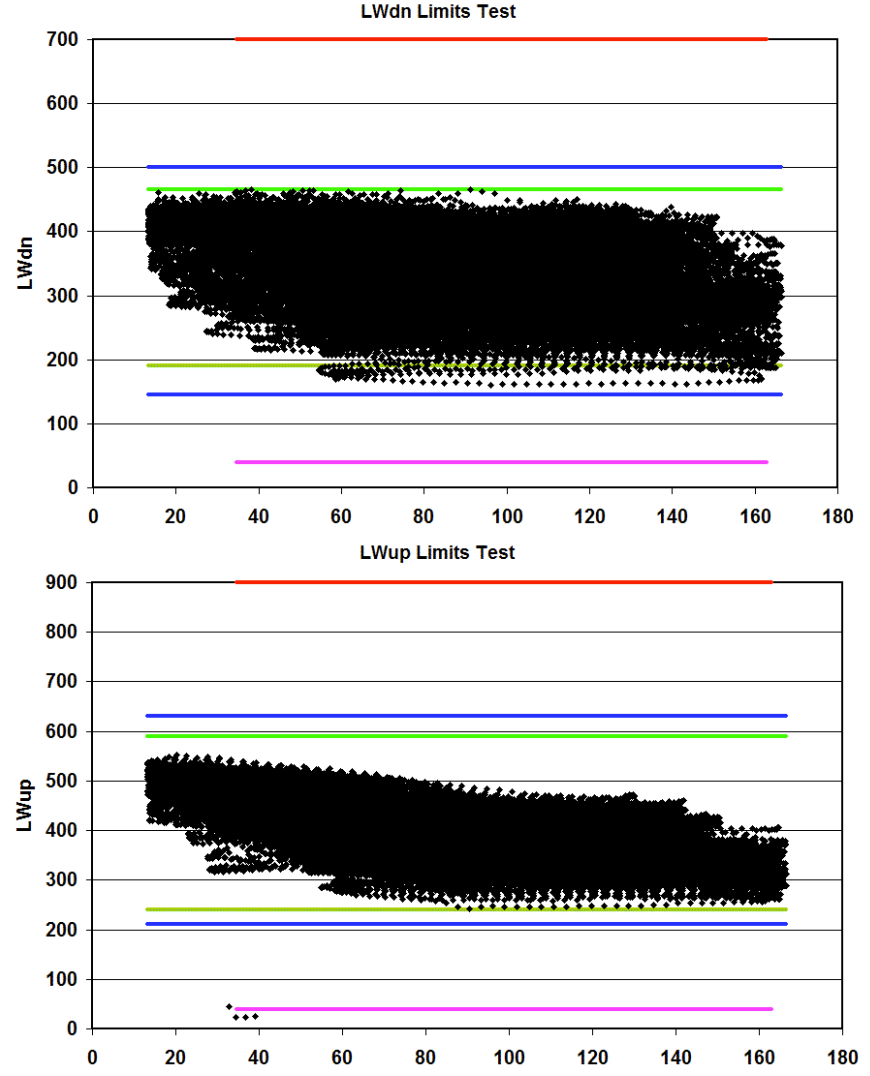

Fig. (8). Simple maximum and minimum limits for testing the downwelling (top) and upwelling (bottom) LW. Red and pink are the BSRN physically possible limits, green and blue are the $1^{\text {st }}$ and $2^{\text {nd }}$ level testing limits, respectively.

With only a few exceptions for the upwelling LW shown in the bottom part of Fig. (8) near $40^{\circ} \mathrm{SZA}$, all the LW data passed the testing illustrated in Figs. $(\mathbf{8 , 9})$. However, the fairly broad range of allowable values between the limits can still allow data with significant error to pass. To test for more subtle problems, our experience has shown that testing the pyrgeometer case and dome temperatures can be used. Since the case and dome temperatures are used to calculate the LW in a non-linear fashion (using the $4^{\text {th }}$ power of the temperatures), a few case or dome temperatures can result in the LW calculations being in error by $10 \mathrm{Wm}^{-2}$ or more. Yet since the ARM radiometers are operated with forced-air degrees error in the ventilators, both the case and dome temperatures should not be too different from the ambient air temperature surrounding the radiometers.
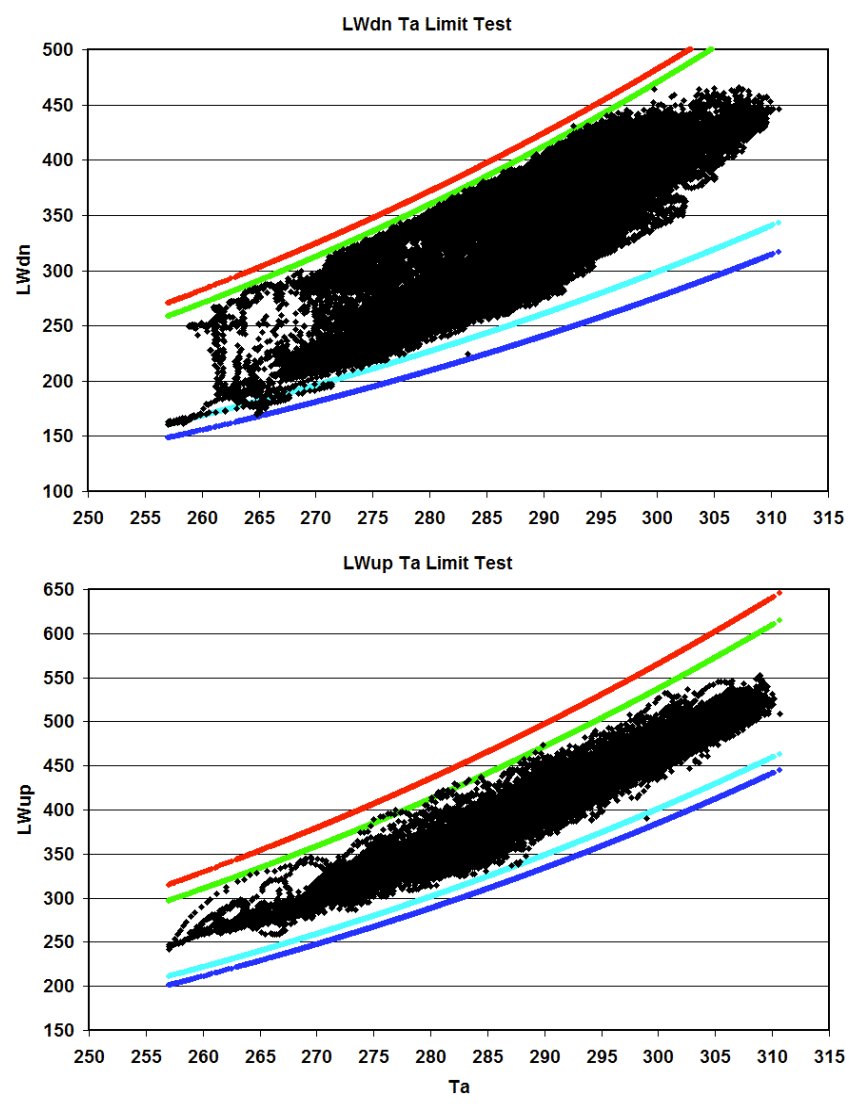

Fig. (9). Downwelling (top) and upwelling (bottom) testing versus air temperature. Green and red represent the $1^{\text {st }}$ and $2^{\text {nd }}$ level maximum, while light and dark blue represent the $1^{\text {st }}$ and $2^{\text {nd }}$ level minimum limits.

Fig. (11) shows comparisons of the case and dome temperatures for the upwelling and downwelling pyrgeometers. As in this example, the upwelling LW instrument's case and dome temperatures tend to have a closer relationship with the air temperature than does the downwelling LW instrument. Nevertheless in both cases fairly close relationships exist between the two. As can be seen, some data for both the upwelling and downwelling instruments failed these tests, and are identified as problematic data not caught by the limits testing shown in Figs. $(\mathbf{8 , 9})$.

We additionally monitor the difference between an individual instrument's case and dome temperatures. Our analyses have shown the generally, with ventilated systems, only a 


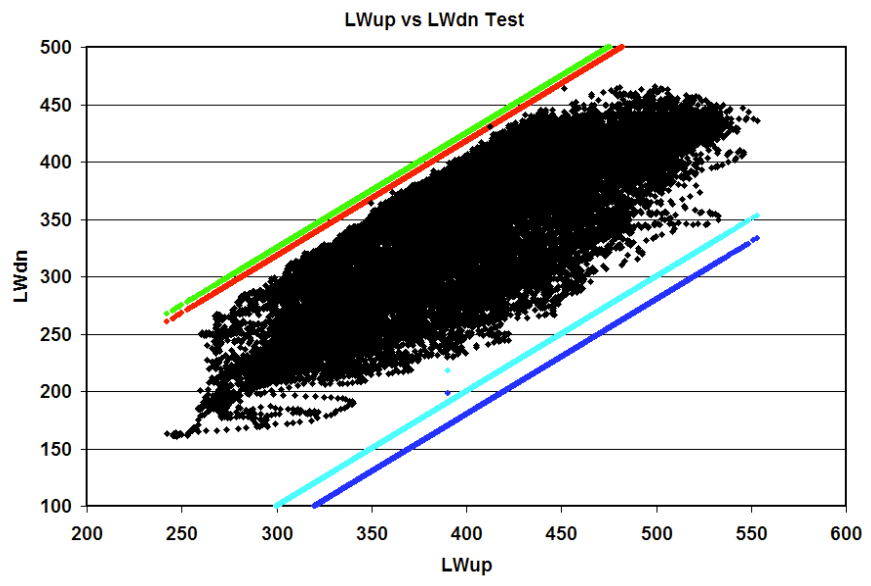

Fig. (10). Same as Fig. (9), but comparing the downwelling and upwelling LW measurements.
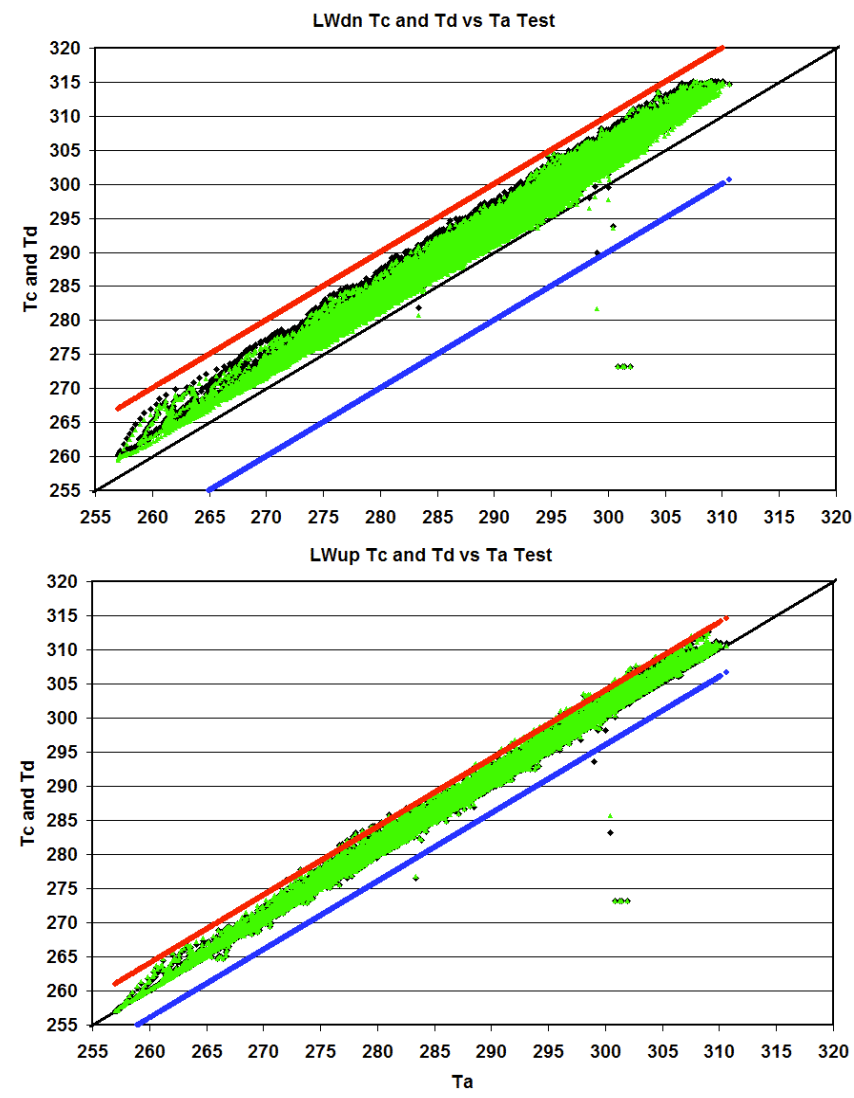

Fig. (11). Comparison of pyrgeometer case (black) and dome (green) temperatures versus air temperature for downwelling (top) and upwelling (bottom) pyrgeometers. Note that most of the case points are hidden by the overlaying dome points. Red and blue lines represent the maximum and minimum limits, respectively. Black line represents the 1:1 line.

relatively small range of difference should be exhibited between these two temperatures under normal conditions. Fig. (12) shows the case minus dome temperature differences for our example data. Note that the dome is generally cooler than the case for the downwelling instrument, though there are times when the dome is slightly warmer. The opposite is generally true for the upwelling instrument. In both cases, if the dome is warmer than the case it is normally only warmer by less than half a degree $\mathrm{C}$. If the dome of the upwelling instrument is cooler than the case, it is also generally only cooler by about half a degree C. For the downwelling instrument, the dome generally is not cooler than the case by more than $2^{\circ} \mathrm{C}$.

For the pyrgeometer testing illustrated in Figs. (11,12), our analyses have shown that test failures are likely to be associated with erroneous data. These test failures indicate that the instrument is not in normal thermal balance, for example under thermal shock conditions such as the start of heavy cold rainfall on a warm summer day, or that the temperature sensors have a problem that precludes accurate measurements. Thus failure of any of these tests causes the associated QC flag to be set to a value of 4 or higher, and the associated data to be set to a value of "-9999.0" in the output files.

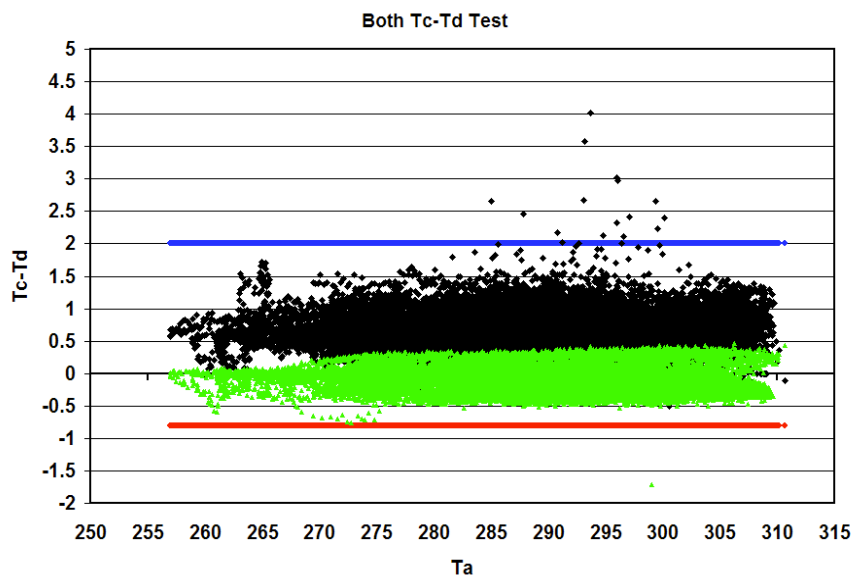

Fig. (12). Plot of case minus dome temperature differences versus air temperature for the downwelling (black) and upwelling (green) pyrgeometers. Blue and red lines represent the maximum and minimum allowable difference, respectively.

\section{DAILY SUMMARIES OF TEST FAILURES}

\section{SW Results}

The QCRad code can be run in near real time, i.e. data can be tested as soon as it is logged, though the more common practice as in ARM is to run the code once per day to test the previous day's data. However, there are some more subtle tendencies and problems that are more likely revealed by studying results over longer time periods such as monthly and yearly. Thus an assessment of a summary of the amount of data failing the various tests for each day over longer time periods can be used to study the persistence of problems or abrupt shifts that might not be evident on a day-to-day operations mode basis. In the following plots, all definitive testing results are only "counted" once at the greatest level of failure.

Fig. (13) shows the daily test results summary for the downwelling unshaded pyranometer for the example year data. As can be seen, the generic correction for IR loss in the unshaded pyranometer still leaves some data failing the physically possible (blue) and $2^{\text {nd }}$ level (green) too low limits. These low failures are all night time data. Additionally a few days failed the Global/Sum ratio test, notably near the 
beginning of May and again in the beginning of September. These data were previously shown in Fig. (4).

Fig. (14) shows the daily test results summary for the Diffuse SW (shaded pyranometer) for the example year (1997) data. As illustrated in Fig. (5), here in this plot it is shown that the diffuse over global SW ratio test failures mostly occurred in the latter part of 1997. For these data, the diffuse has been corrected for IR loss through the ARM Diffuse Correction VAP [4], resulting in only very few "too low" failures. Note some failures of the $2^{\text {nd }}$ level maximum tests early in October (light blue). These failures correspond to the tracker not properly tracking the sun, as shown in Fig. (15). Fig. (15) also shows only a few cases where the direct SW falls below the $2^{\text {nd }}$ level "too low" limit.

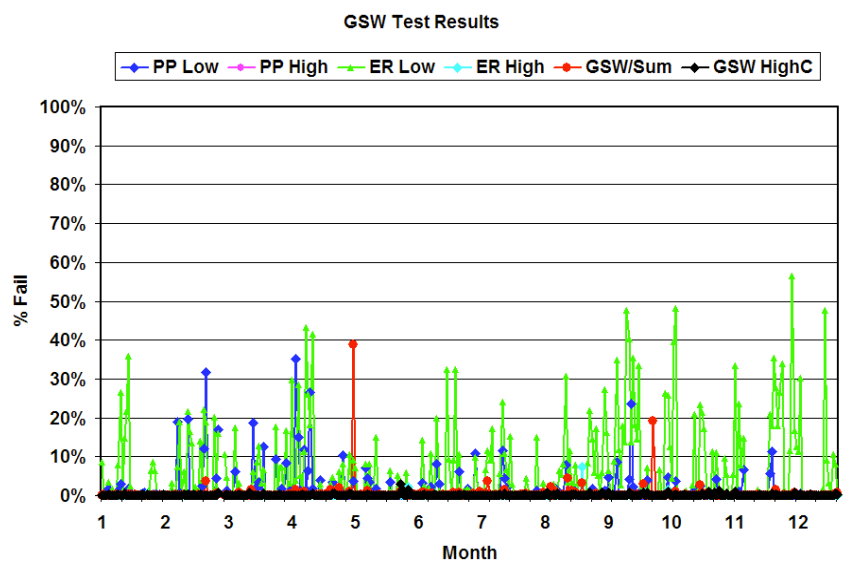

Fig. (13). Daily summary of the percentage of various testing failures relative to the amount of possible data for the global (unshaded) pyranometer measurements. Blue and pink represent the low and high BSRN Physically Possible (PP) test failures, respectively. Green represents 2nd level Extremely rare (ER) lower limit, light blue the upper level 2nd level limit, black the upper 1st level configurable (C) limit. Red denotes the global over sum SW ratio testing as illustrated in Fig. (4).

Dif SW Test Results

$\rightarrow$ PP Low $\rightarrow$ - PP High $\_$ER Low - ER High $\rightarrow-$ Diff/Gsw $\rightarrow-$ Dif HighC

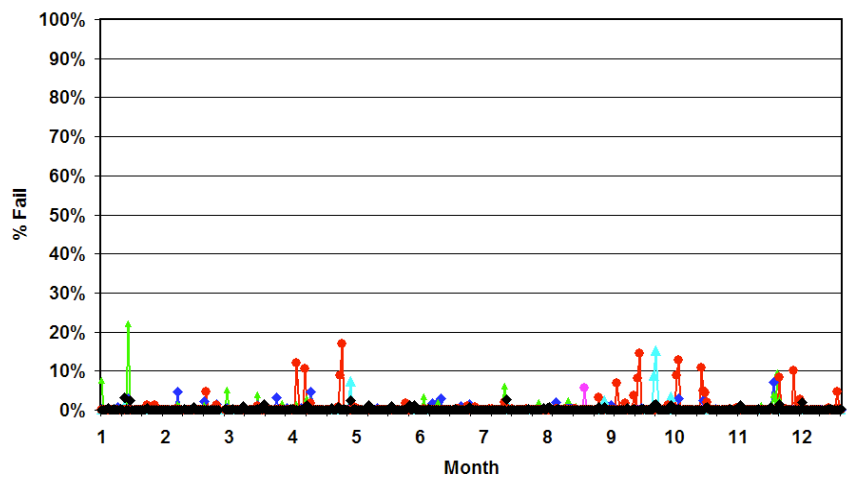

Fig. (14). Same as Fig. (13), but for diffuse SW tests. Note that in this plot red denotes diffuse over total SW ratio testing results as illustrated in Fig. (5).

Fig. (16) shows the daily summary results for upwelling SW testing. We note here brief periods of anomalously large upwelling SW during April, early July, August, and Septem-

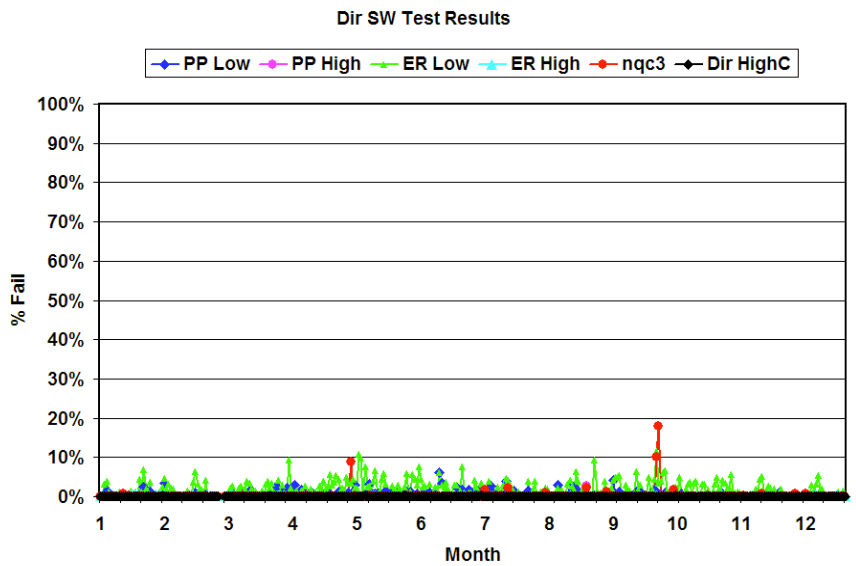

Fig. (15). Same as Fig. (14), but for direct SW tests. Note that in this plot red denotes solar tracker alignment testing results as illustrated in Fig. (2).

ber of 1997 . These months are not typified by snowfall events at the SGP, thus these results cannot be attributed to a high albedo surface, but rather to other causes (Figs. 6,7) that preclude these data being accurate measurements of upwelling SW. Note also a brief period in August where the upwelling SW measurements were anomalously low during night time hours, likely indicating an IR loss offset.

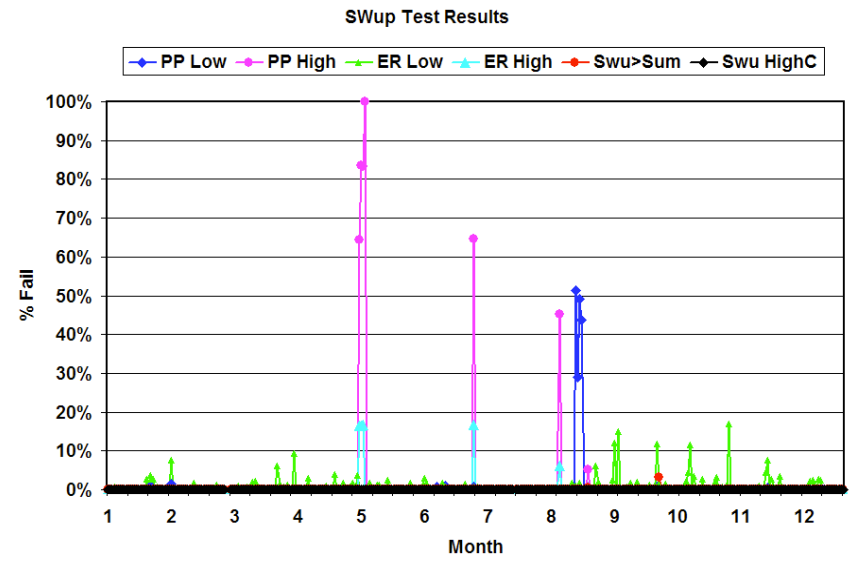

Fig. (16). Same as Fig. (14), but for upwelling SW tests. Note that in this plot red denotes upwelling SW is greater than the downwelling SW plus $25 \mathrm{Wm}^{-2}$.

\section{LW Results}

For the LW, Figs. $(\mathbf{1 7 , 1 9 )}$ show the summary results of the simple limits testing illustrated in Fig. (8) for the downwelling and upwelling LW, respectively. For the downwelling LW (Fig. 17), the problem data (too low) occurred in January of 1997, whereas for the upwelling LW (Fig. 19) problems (too high) occurred primarily in late July. Additional downwelling LW anomalously low data during the January period were caught by the comparison to air temperature testing shown in Fig. (18). For the upwelling LW, some data were shown to be anomalously high versus air temperature (Fig. 20) in March and April of 1997.

Fig. (21) shows the results of the testing of the pyrgeometer case and dome temperatures versus air temperature, and the testing of the air temperatures themselves. In this plot, the results for both the upwelling and downwelling pyr- 


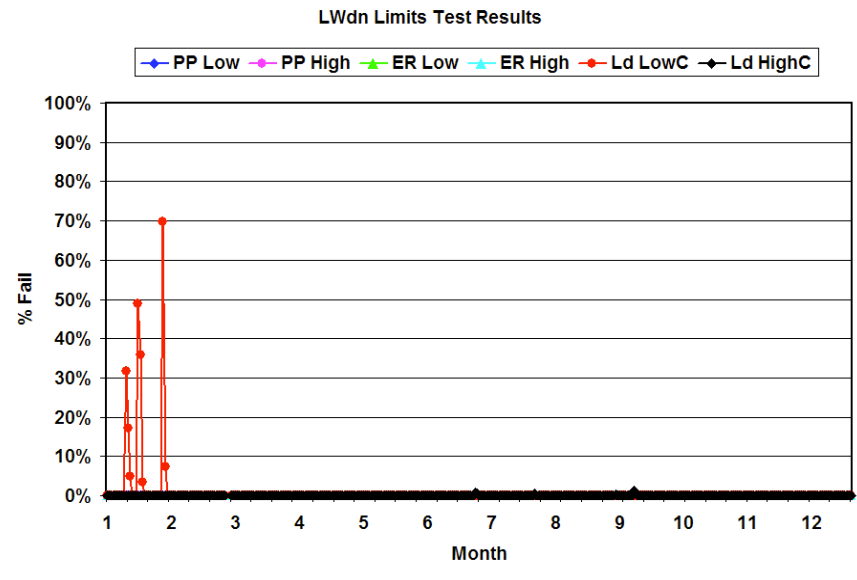

Fig. (17). Results for downwelling LW simple limits tests, where PP denotes the BSRN Physically Possible limits, ER denotes the 2nd level configurable Extremely Rare limits, and $\mathrm{C}$ denotes the 1st level configurable limits.

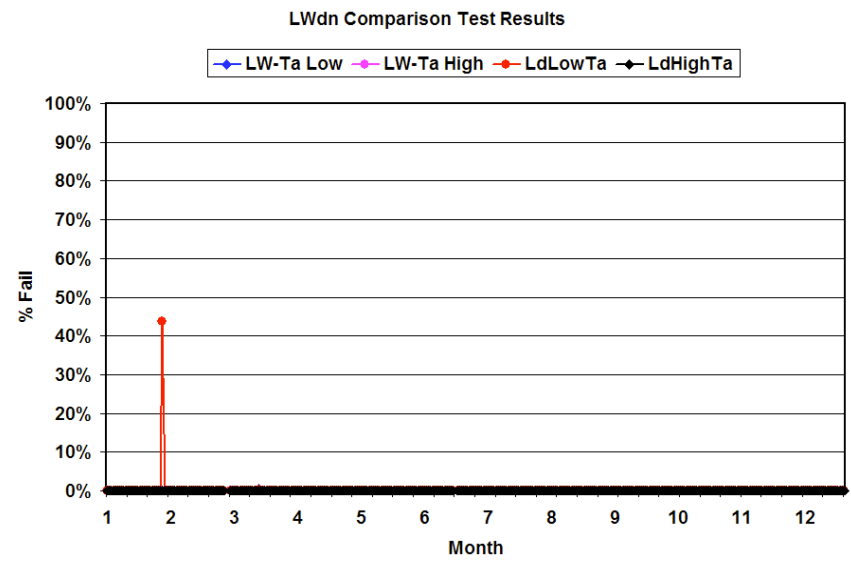

Fig. (18). Limits test results using air temperature measurements for downwelling LW. Blue and pink represent the minimum and maximum 2nd level test limits, respectively; red and black represent the minimum and maximum 1 st level test limits, respectively.

geometers are summed together. This plot shows some instances of the case and/or dome temperatures differing from the air temperatures more than the set limits (Fig. 11) primarily through the first $2 / 3$ of 1997 . Similarly, some very few times the difference between the pyrgeometer case and dome temperatures fell outside expected limits. The only time that the air temperature data itself failed to agree within $15^{\circ} \mathrm{C}$ of the average of the pyrgeometer case and dome temperatures occurred on one day near the beginning of September.

\section{SUMMARY OF ALL RESULTS}

Fig. (22) shows a summary of all test failures by measurement. For example, all the failures of the various testing of the total SW are added up and displayed in blue on the plot. Most of the problems with the downwelling LW measurements occurred early in the study year, while most of the upwelling SW problems occurred in the middle of the year. One day in the beginning of September exhibits significant test failures for the total, diffuse, and upwelling SW, indica-

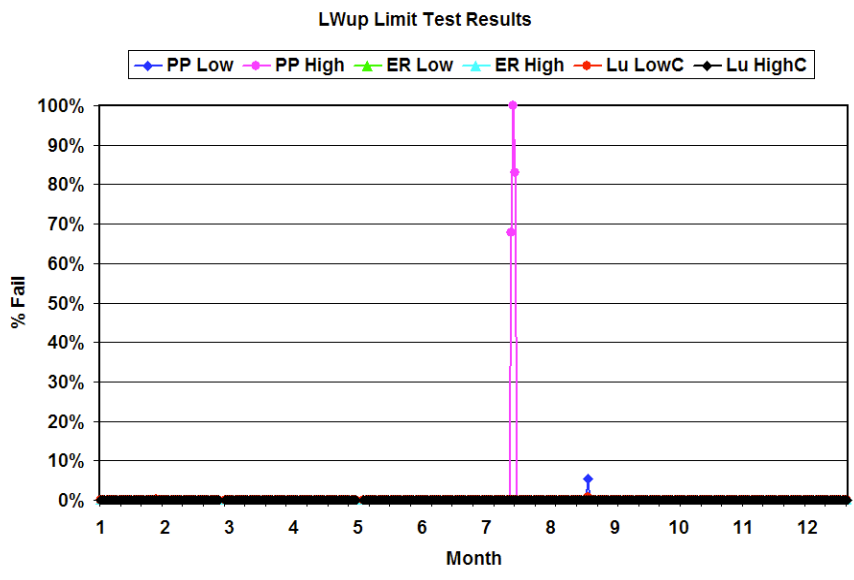

Fig. (19). Same as Fig. (17), but for upwelling LW.

tive of a system problem rather than individual instrument problems. In summary, the QCRad VAP provides useful quality analysis results for both the daily and the longer-term runs of the code. Each of these run-modes can be used to examine different aspects of data quality management and monitoring of the various radiometer systems.

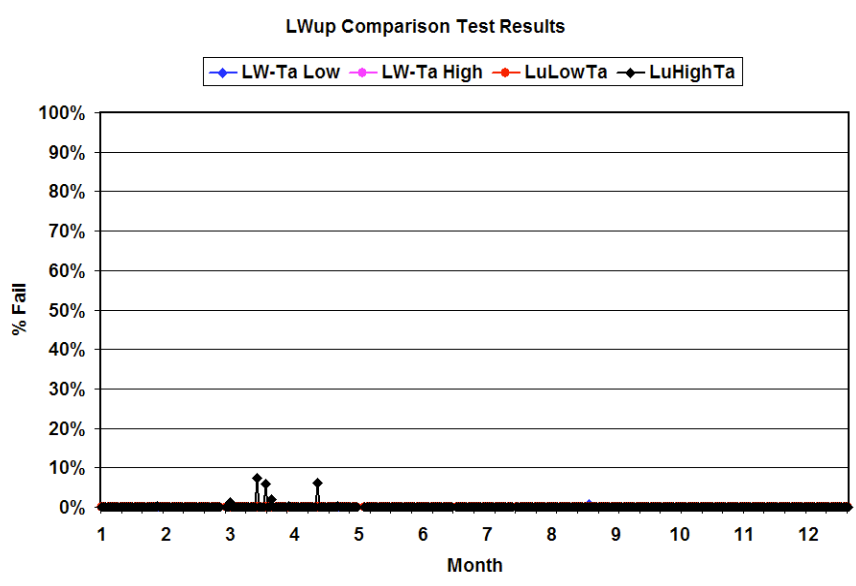

Fig. (20). Same as Fig. (18), but for upwelling LW.

\section{CONCLUSIONS}

The QCRad algorithm is intended to provide an automated assessment of the quality of surface broadband radiation measurements. The algorithm will process data in near real time, though is more commonly used on a daily basis, as a tool to identify problems in operation of the instruments so that appropriate measures can be quickly taken. However, as shown in the previous sections, the compiled flagging results can be useful in giving an overall assessment view of the longer term data record. Though we have not shown an example here, perhaps more subtle problems can be identified through longer-term assessment. For instance given a generic correction for IR loss for global SW, we show there are still some occurrences of negative night time offset larger than -2 $\mathrm{Wm}^{-2}$ (Fig. 13). Thus some occurrences during daily testing are expected. But over a year, a slow tendency for increasing occurrences might signal a problem such as a drift of the data logger channel voltage or slow corrosion of the wiring connector. Combining these longer-term assessment ideas with the current development of an IR Loss correction VAP 


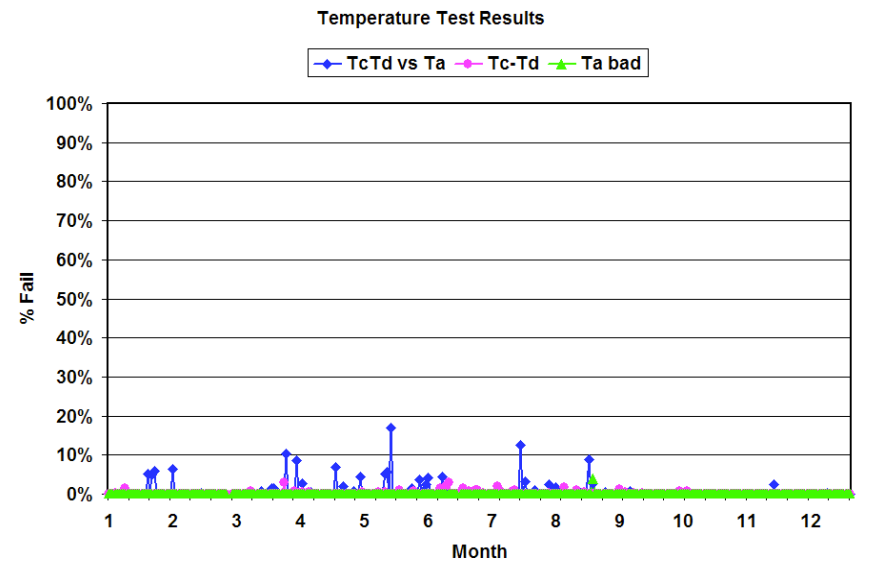

Fig. (21). Results for testing of the pyrgeometer case and dome temperatures, and air temperatures. Blue represents a summary of all failures of both upwelling and downwelling pyrgeometers with respect to the individual case and dome temperatures themselves. Pink represents a summary of all failures of both the upwelling and downwelling pyrgeometer case-dome difference testing. Green represents failures of the air temperature measurements themselves.

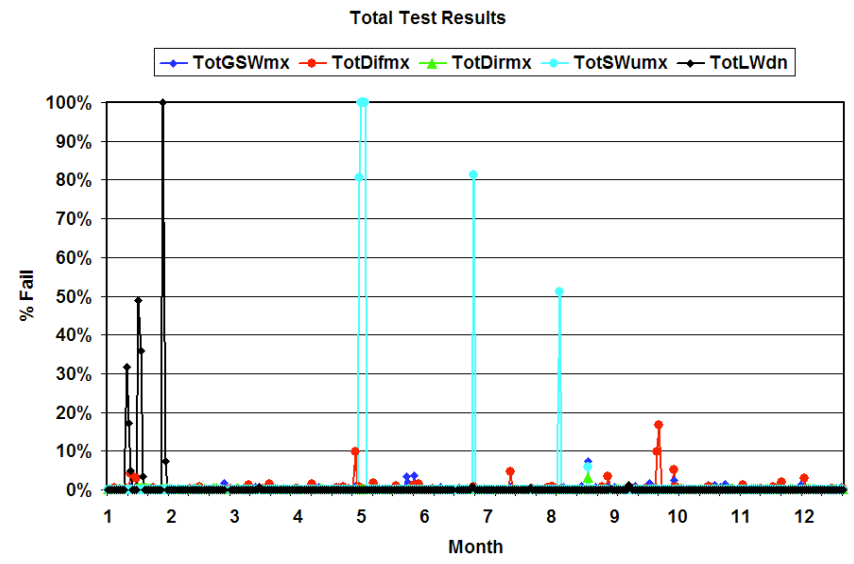

Fig. (22). Summary of all testing results for the total SW (blue), diffuse SW (red), direct SW (green) upwelling SW (light blue), and downwelling LW for the example year of 1997 for the SGP Central Facility.

for unshaded pyranometer measurements, we intend to pursue yearly evaluations of ARM surface radiation measurements. The longer-term analyses will afford the opportunity to provide overall reporting of problematic data.

\section{ACKNOWLEDGEMENTS}

The authors acknowledge the support of the Office of Science (BER) of the U.S. Department of Energy as part of the ARM Program. Recognition is also extended to those responsible for the operation and maintenance of the instruments that produced the data used in this study; their diligent and dedicated efforts are often underappreciated.

\section{APPENDIX 1: DESCRIPTION OF QC FLAG VALUES}

The QCRad algorithm used defined QC flag values that describe the severity and direction (too low or too high) of the testing results. What follows is a test-by-test summary of the flag values and the associated meaning.
Flag Value: Related to Type test:

5-6 Global Physical Limits (PP)

3-4 User configurable (UC2) 2nd level tests,

1-2 User configurable (UC1) 1st level tests and non-definitive tests

Non-definitive means that while a comparison test may fail, it is unknown which of the values compared might be the problematic one causing the test failure.

The tests and flags are set restrictively in descending order. In other words, if a value fails a BSRN Physically Possible (PP) limit, then the $2^{\text {nd }}$ level Extremely Rare (ER) and $1^{\text {st }}$ level user configurable (UC) tests are not performed, as the data will always fail these tests as well. Thus, the QC flag reflects the greatest severity of test failure value.

QC1-QC6 (GSW, Diffuse SW, Direct SW, SWup, LWdn, and LWup basic limits tests)

-1-missing data or test not possible

0 -No test failures

1-too low (UC1)

2-too high (UC1)

3-too low (UC2)

4-too high (UC2)

5-too low (PP)

6-too high (PP)

9-“tracker off” (QC2 and QC3)

QC7-GSW/Sum test [non-definitive]

$-1=$ test not possible

$0=$ No test failures

$1=\mathrm{Z}<75^{\circ} ; \mathrm{GSW} / \mathrm{Sum}<0.92$, or GSW/Sum $>1.08$, Sum $>$ $50 \mathrm{Wm}^{-2}$

$2=93^{\circ}>\mathrm{Z}>75^{\circ} ; \mathrm{GSW} / \mathrm{Sum}<0.85$, or GSW $/ \mathrm{Sum}>1.15$, Sum $>50 \mathrm{Wm}^{-2}$

QC8-Dif/GSW test [non-definitive]

$-1=$ test not possible

$0=$ No test failures

$1=\mathrm{Z}<75^{\circ} ; \mathrm{Dif} / \mathrm{GSW}>1.05, \mathrm{GSW}>50 \mathrm{Wm}^{-2}$

$2=93^{\circ}>\mathrm{Z}>75^{\circ} ; \mathrm{Dif} / \mathrm{GSW}>1.10, \mathrm{GSW}>50 \mathrm{Wm}^{-2}$

QC9-SWup vs Sum SW test

$-1=$ test not possible 


$$
\begin{aligned}
& 0=\text { No test failures } \\
& 1=\text { Sum or GSW }>50 \mathrm{Wm}^{-2} ; \mathrm{SWup}>\mathrm{C} 9 * \mathrm{Sum}+25 \mathrm{Wm}^{-2}, \\
& \mathrm{Ta}>=\text { Tsnw } \\
& 2=\text { Sum or GSW }>50 \mathrm{Wm}^{-2} ; \mathrm{SWup}>\mathrm{C} 10 * \mathrm{Sum}+25 \mathrm{Wm}^{-2}, \\
& \text { Ta }<\text { Tsnw } \\
& 3=\text { Sum }>50 \mathrm{Wm}^{-2} ; \mathrm{SWup}>\mathrm{Sum} \\
& 4=\text { Sum not avail, GSW }>50 \mathrm{Wm}^{-2} ; \mathrm{SWup}>\mathrm{GSW} \\
& 5=\text { Sum AND GSW }>50 \mathrm{Wm}^{-2} \text {; SWup }>\text { Sum AND SWup } \\
& >\text { GSW; Swup "bad" }
\end{aligned}
$$

$$
\begin{aligned}
& \text { QC10-LWdn to Ta test } \\
& -1=\text { test not possible } \\
& 0=\text { No test failures } \\
& 1=\text { Ta OK; LWdn }<(\mathrm{C} 11 * \text { sigma*Ta }) \\
& 2=\mathrm{Ta} \text { OK } ; \mathrm{LWdn}>\left(\text { sigma*Ta }{ }^{4}+\mathrm{C} 12\right) \\
& 3=\mathrm{Ta} \text { OK } ; \mathrm{LWdn}<\left(\mathrm{D} 11 * \operatorname{sigma}^{*} \mathrm{Ta}^{4}\right) \\
& 4=\mathrm{Ta} \text { OK } ; \mathrm{LWdn}>\left(\operatorname{sigma} \mathrm{Ta}^{4}+\mathrm{D} 12\right)
\end{aligned}
$$

QC11-LWup to Ta test

$-1=$ test not possible

$0=$ No test failures

$1=$ Ta OK $;$ LWup $<\left(\right.$ sigma $\left.*(\mathrm{Ta}-\mathrm{C} 13)^{4}\right)$

$2=$ Ta OK; LWup $>\left(\operatorname{sigma} *(\mathrm{Ta}+\mathrm{C} 14)^{4}\right)$

$3=$ Ta OK; LWup $<\left(\right.$ sigma* $\left.(\text { Ta-D13 })^{4}\right)$

$4=$ Ta OK; LWup $>\left(\operatorname{sigma}^{*}(\mathrm{Ta}+\mathrm{D} 14)^{4}\right)$

QC12-LWdn to LWup test

$-1=$ test not possible

$0=$ No test failures

$1=1$ wdn $<$ lwup-C15

$2=1$ wdn $>1$ lwup + C16

$3=\operatorname{lwdn}<1$ wup-D15

$4=1$ wdn $>1$ lwup + D16

QC13-LWdn Tc vs Ta

$-1=$ test not possible

$0=$ No test failures

$3=\mathrm{Tc}<\mathrm{Ta}-\mathrm{C} 17$
$4=\mathrm{Tc}>\mathrm{Ta}+\mathrm{C} 17$

QC14-LWdn Td vs Ta

$-1=$ test not possible

$0=$ No test failures

$3=\mathrm{Td}<\mathrm{Ta}-\mathrm{C} 17$

$4=\mathrm{Td}>\mathrm{Ta}+\mathrm{C} 17$

QC15-LWup Te vs Ta

$-1=$ test not possible

$0=$ No test failures

$3=\mathrm{Tc}<\mathrm{Ta}-\mathrm{C} 17$

$4=\mathrm{Tc}>\mathrm{Ta}+\mathrm{C} 17$

QC16-LWup Td vs Ta

$-1=$ test not possible

$0=$ No test failures

$3=\mathrm{Td}<\mathrm{Ta}-\mathrm{C} 17$

$4=\mathrm{Td}>\mathrm{Ta}+\mathrm{C} 17$

QC17-LWdn Tc vs Td

$-1=$ test not possible

$0=$ No test failures

$3=(\mathrm{Tc}-\mathrm{Td})<\mathrm{C} 18$

$4=(\mathrm{Tc}-\mathrm{Td})>\mathrm{C} 19$

QC18-LWup Tc vs Td

$-1=$ test not possible

$0=$ No test failures

$3=(\mathrm{Tc}-\mathrm{Td})<\mathrm{C} 18$

$4=(\mathrm{Tc}-\mathrm{Td})>\mathrm{C} 19$

QC19-Ta testing

$-1=$ test not possible, (no Ta)

$0=$ No test failures

$1=\mathrm{Ta}>350 \mathrm{~K}$ or $\mathrm{Ta}<170 \mathrm{~K}$

$2=$ Ta more than Tavg $+/-20 \mathrm{~K}$ 


\section{APPENDIX 2: TEST CONFIGURATION LIMITS DETERMINED FOR ARM DATA}

The configuration limits are derived from historical data analyses at each site. Table 1 shows the testing limits determined for the three ARM sites located in the Southern Great Plains (SGP) of the continental USA, the Tropical Western Pacific (TWP), and the North Slope of Alaska (NSA). The two sets of values listed for each ARM site represents the $1^{\text {st }}(\mathrm{C})$ and $2 \mathrm{nd}$ level (D) configurable limits (where appropriate), respectively.

Table 1. Configurable Limits for Each ARM Site

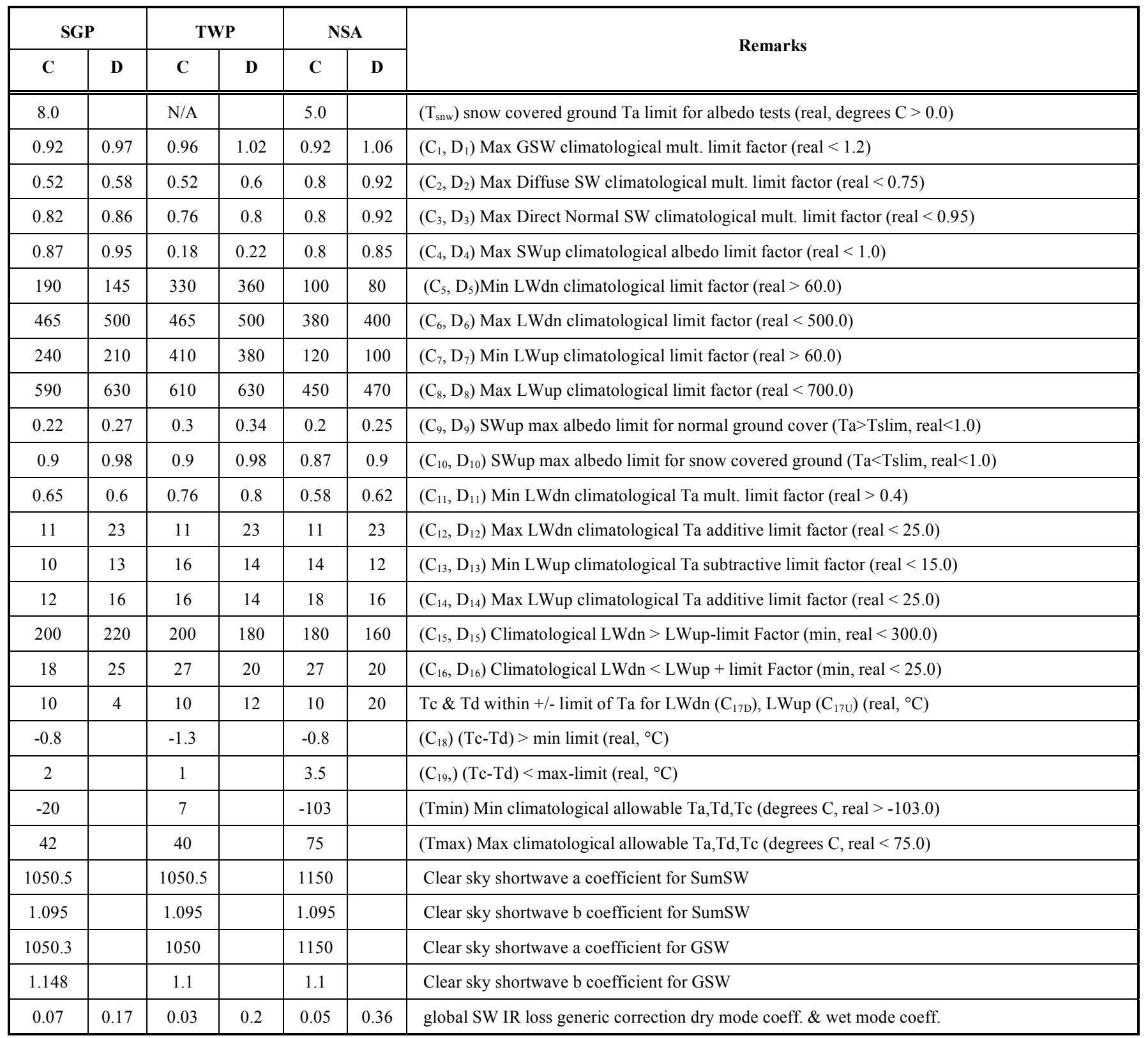

\section{REFERENCES}

[1] Ackerman TP, Stokes GM. The atmospheric radiation measurement program. Phys Today 2003; 56: 38-44.

[2] Augustine JA, DeLuisi JJ, Long CN. SURFRAD-A National Surface Radiation Budget Network for Atmospheric Research. Bull Am Meteorol Soc 2000; 81: 2341-2357.

[3] Ohmura A, Dutton EG, Forgan B, et al . Baseline Surface Radiation Network (BSRN/WCRP): New Precision Radiometry for Climate Research. Bull Am Meteorol Soc 1998; 79(10): 2115-2136.

[4] Younkin K, Long CN. Improved Correction of IR Loss in Diffuse Shortwave Measurements: An ARM Value Added Product. Atmospheric Radiation Measurement Program Technical Report,
ARM TR-009 2004; Available via http://www.arm.gov/publications/techreports. stm.

[5] Shi Y, Long CN. Best Estimate Radiation Flux Value Added Product: Algorithm Operational Details and Explanations. Atmospheric Radiation Measurement Program Technical Report, ARM TR-008 2002; Available via http://www.arm.gov/publications/techreports.stm.

[6] WMO (World Meteorological Organization). Guide to Meteorological Instruments and Methods of Observation. WMO-No8 1996, (6th edition), World Meteorological Organization, Geneva.

[7] Long CN, Dutton EG. BSRN Global Network recommended QC tests, V2.0. BSRN Technical Report 2002: available via (http://ezksun3.ethz. ch/bsrn/admin/ dokus/ qualitycheck.pdf). 
[8] Long CN, Ackerman TP. Identification of Clear Skies from Broadband Pyranometer Measurements and Calculation of Downwelling Shortwave Cloud Effects. J Geophys Res 2000; 105(D12): 15609-15626.

[9] Long CN, Gaustad KL. The Shortwave (SW) Clear-Sky Detection and Fitting Algorithm: Algorithm Operational Details and Explanations. Atmospheric Radiation Measurement Program Technical Report ARM TR-004 2004; Available via http://www.arm.gov/ publications/techreports.stm.

[10] Ohmura A. Physical basis for the temperature-based melt-index method. J Appl Meteorol 2001; 40: 753- 761.

[11] Shi Y, Long CN. Preliminary Analysis of Surface Radiation Measurement Data Quality at the SGP Extended Facilities. 13th ARM
Science Team Meeting Proceedings, Broomfield, Colorado, March 31-April 4, 2003

[12] Shi Y, Long CN. Surface Radiation Measurement Data Quality Assessment at the ARM TWP and NSA Sites. 16th ARM Science Team Meeting Proceedings, Albuquerque, New Mexico, March 27 31, 2006.

[13] Shi Y, Long CN. Total Downwelling SW IR Loss Correction at ARM Sites. 17th ARM Science Team Meeting Proceedings, Monterey, California, March 26-30, 2007.

[14] Reda I, Hickey J, Long CN, et al. Using a blackbody to calculate net-longwave responsivity of shortwave solar pyranometers to correct for their thermal offset error during outdoor calibration using the component sum method. J Technol 2005; 22(10): 1531-1540. 